\title{
NEO-FFI: Psychometric Properties of a Short Personality Inventory in Portuguese Context
}

\author{
NEO-FFI: Propriedades Psicométricas de um Inventário Reduzido \\ de Personalidade no Contexto Português
}

\author{
Eunice Magalhães*, ${ }^{a}$, Ana Salgueira ${ }^{a}$, António-José Gonzalez ${ }^{b}$, José Joaquim Costa ${ }^{c}$, \\ Manuel João Costa ${ }^{a}$, Patrício Costa ${ }^{a} \&$ Margarida Pedroso de Lima ${ }^{c}$ \\ ${ }^{a}$ ICVS/3B's Associated Laboratory, School of Health Sciences, University of Minho, Braga, Portugal, \\ ${ }^{b}$ ISPA-Instituto Universitário de Ciências Psicológicas, Sociais e da Vida, Lisboa, Portugal \\ $\&{ }^{c}$ Universidade de Coimbra, Coimbra, Portugal
}

\begin{abstract}
The aim of this study was to assess the psychometric properties (validity and reliability) of the Portuguese adaptation of the NEO Five-Factor Inventory (NEO-FFI) and to compare the obtained structure to the original North American version. The methods of analysis used for cross-validation of the factorial structure were the Principal Axis Factoring (PAF) and the Confirmatory Factor Analysis (CFA). PAF reproduced the original structure of NEO-FFI and CFA revealed a satisfactory fit of single-factor models for the five dimensions. The reliability analysis showed high values of internal consistency which are congruent with previous international adaptations of the NEO-FFI. Multidimensional analysis showed significant main effects of gender and academic qualifications on personality using age as covariant. The findings suggest that the Portuguese version of the NEO-FFI is a reliable instrument to measure the five dimensions of personality.

Keywords: NEO-FFI, personality, psychometrics, Portuguese context.

Resumo

O objetivo deste estudo foi avaliar as propriedades psicométricas (validade e fidelidade) da adaptação portuguesa do NEO-FFI e comparar a estrutura obtida com a versão original americana. Como métodos para a validação cruzada da estrutura fatorial foram usados a Análise Fatorial de Eixos Principais (PAF) e uma Análise Fatorial Confirmatória (CFA). A PAF reproduziu a estrutura original do NEO-FFI e a CFA revelou modelos uni-factoriais de ajustamento satisfatório para cada uma das cinco dimensões. A análise de fidelidade revelou elevados valores de consistência interna, congruentes com as adaptações prévias internacionais do NEO-FFI. A análise multidimensional revelou efeitos principais significativos do género e das qualificações académicas na personalidade, usando a idade como co-variante. Os resultados sugerem que a versão portuguesa do NEO-FFI é um instrumento fiável para medir as cinco dimensões da personalidade.

Palavras-chave: NEO-FFI, personalidade, psicometria, contexto português.
\end{abstract}

The Five-Factor Model (FFM) organizes human personality traits across cultures under a comprehensive framework (Costa \& McCrae, 1992; Muck, Hell, \& Gosling, 2007) of five dimensions - Neuroticism, Extraversion, Openness to Experience, Agreeableness and Conscientiousness. The dimensions are empirical generalizations that reflect enduring differences in behavioural, emo-

\footnotetext{
* Mailing address: School of Health Sciences, University of Minho, Campus de Gualtar, 4700 Braga, Portugal. E-mail: nicemagalhaes@gmail.com, anasalgueira@ ecsaude.uminho.pt, gonzalez@ispa.pt,jjcosta@fpce. uc.pt,mmcosta@ecsaude.uminho.pt,pcosta@ecsaude. uminho.pt and mplima@fpce.uc.pt.

Eunice Magalhães, Current affiliation - Instituto Universitário de Lisboa (ISCTE-IUL), Cis-IUL, Lisboa, Portugal
}

tional and cognitive patterns between individuals (Costa \& McCrae, 1992; Rolland, Parker, \& Stumpf, 1998). The Revised NEO Personality Inventory (NEO-PI-R; Costa \& McCrae, 1992) is a measure of the five dimensions of personality and of the six facets that underlie each dimension. The original NEO-PI-R has high internal consistency levels, good test-retest reliabilities as well as convergent and discriminant validity and the translations available in several idioms are also psychometrically sound (e.g., McCrae et al., 1999; McCrae, Terracciano, \& Personality Profiles of Cultures Project, 2005).

The NEO-PI-R is a 240-item measure of the FFM's and takes about 45 minutes to complete. The NEO-Five Factor Inventory (NEO-FFI), with 60 items is a shortened version of the NEO-PI-R with equivalent comprehensive- 
Magalhães, E., Salgueira, A., Gonzalez, A-J., Costa, J. J., Costa, M. J., Costa, P. \& Lima, M. P. (2014). NEO-FFI: Psychometric Properties of a Short Personality Inventory in Portuguese Context.

ness, but amenable to be applied in research projects that require the administration of a brief instrument to measure the FFM (e.g., Aluja, Garcia, Rossier, \& Garcia, 2005; Lucas \& Donnellan, 2009). The original NEO-FFI's reliability has been demonstrated in the North American context (Costa \& McCrae, 1989), with values of internal consistency ranging from .68 to .86 , and the same is true for adaptations developed for other cultures (e.g., Aluja et al., 2005 found values ranging between .70 and .87 ; Egan, Deary, \& Austin, 2000, found values ranging between .72 and .87). Alike the NEO-PI-R, the NEO-FFI is cross-culturally stable (Aluja et al., 2005; Lucas \& Donnellan, 2009) although there are some exceptions related to failures in the reproduction of structure (e.g., Aluja et al., 2005; Furham, 1997; Korner et al., 2008). The following strategies have addressed reliability and validity issues with initial versions of the NEO-FFI (McCrae \& Costa, 2004): (a) minimization the effects of acquiescence; (b) increase the correlations with NEO-PI-R factor scores; (c) diversification of the item content by selecting items from underrepresented facets, and increase the intelligibility of the items. Validity and reliability (Cronbach alpha range from .75 to .82 ) of the new version has been demonstrated

(McCrae \& Costa, 2004).

A Portuguese adaptation of NEO-PI-R is available with good psychometric properties (Lima, 1997). The factor structure of the Portuguese NEO-PI-R corresponded to the Five-Factor Model, as revealed by varimax-rotated principal components analysis. The factors explained $21 \%$ of the variance. This is similar to the North American context, in which the five factors could explain $23 \%$ of the variance (Costa, McCrae, \& Dye, 1991). When the 30 facets were factored, five components could account for $55 \%$ of the variance as compared to $58 \%$ reported by Costa et al. (1991). Procrustes rotation showed that all factors and all variables had statistically significant patterns of loadings. Overall structures of the Portuguese and the North American were similar. The process of translation complied with international guidelines (e.g., Van de Vijver \& Hambleton, 1996):

1. Translation by four Portuguese university faculty fluent in English with various backgrounds on social sciences;

2. Pilot testing with a small group of 20 subjects and subsequent item editing and reviewing to improve clarity and comprehension by the reader;

3. Determination of the judgmental evidence using a back-translation of the final version by an English native fluent in Portuguese and

4. Approval by the authors of the original instrument after minor modifications (Lima, 1997). The application of the NEO-PI-R adapted to Portuguese, replicated the FFM, and variations in personality related to age, occupation, education and gender equivalent to many countries: (a) Women were associated with higher scores for Neuroticism and Agreeableness and lower for Extraversion; (b) Older subjects were less neurotic, extravert and open to experience; (c) As compared to non-students, students were more extraverts, neurotic and open to experience and less agreeable and conscientious (Lima, 1997; McCrae, Costa, Del Pilar, Rolland, \& Parker, 1998).

The present study reports the development of the Portuguese NEO-FFI to meet research demands in Portugal. Like the original version, the Portuguese NEOFFI was created with the 12 items of NEO-PI-R from each dimension with the highest correlations with validimax factor scores (McCrae \& Costa, 2004). The primary research objectives of this study were: (a) to assess the psychometric properties of the Portuguese NEO-FFI, (b) to analyze the structure of the Portuguese NEO-FFI relatively to the original North American version.

\section{Materials and Method}

\section{Sample}

Thousand two hundred and ninety participants answered the Portuguese NEO-FFI. The study excluded subjects with missing values from the analysis (absence of data for more than 30 items of the scale, $N=53$ ) and for participants with lower than 30 missings $(n=9)$ a regression imputation (according to each of the personality's dimensions) was performed. The absolute values of skewness and kurtosis for all items were within the acceptable range of the normal distribution (lower than 3.0 and 8.0, respectively; Kline, 2005).

The sample included 1237 subjects, 843 were females (68.4\%) and 390 males (31.6\%), with ages within the range of 18-92 years old $(M=42.95 ; S D=22.77)$. Participants' educational levels (according to International Standard Classification of Education) included Primary/Level 1 (27.2\%), Lower Secondary/Level 2 (9.3\%), Secondary/ Level $3(42.9 \%)$ and Tertiary Education/Level 5 and 6 $(16.7 \%)$. The sample and the Portuguese population have similar distributions for further academic qualifications and age groups as reported by Institute of National Statistics (2010; the entity responsible for ensuring the production and dissemination of official statistical information), apart from slightly over-representations of Secondary Education $(+27 \%)$, of age group of $18-24$ years old $(+25.6 \%)$ and females $(+16.3 \%)$.

\section{Measure}

The Portuguese NEO-FFI includes 60 items and can be completed in approximately 15 minutes. The answer format is a 5-point likert scale ranging from 0 (strongly disagree), 1 (disagree), 2 (neutral), 3 (agree) to 4 (strongly agree).

\section{Procedures}

Participants answered voluntarily and individually (926 answered on paper and 311 online in a secured computer facility) and confidentiality was guaranteed. In Portugal, the law on experiments on humans does not require 
ethics approval for studies developed outside biomedical or health sciences which involve human persons the goal of developing knowledge. College age participants were recruited in university contexts and responses from older subjects were collected with snowball sampling started by students in the context of a course assignment. Confidentiality was guaranteed. Data were analysed with PASW Statistics 18 (Predictive Analytics Software) and AMOS 18 (Arbuckle, 2009). The factorial structure of NEO-FFI was tested with a holdout method for crossvalidation randomizing the full sample into two subsamples of 619 participants (A) and 618 (B). A Principal Axis Factoring (PAF) was applied to extract the personality dimensions in Sub-sample A. In sub-sample B, crossvalidated factor models of Confirmatory Factor Analysis (CFA) were applied (Sample 1=309; Sample 2=309) with Maximum Likelihood estimation method for each dimension (as Gignac, Bates, \& Jang, 2007) and for all five factors. The reliability of the five dimensions was tested with Cronbach's alpha and with estimates of an equally weighted composite (as Gignac et al., 2007). Additionally, as personality factors structure can be different considering education level, a PAF was performed with whole sample $(N=1237)$ divided into two groups of education: Level 1 and 2 vs Level 3, 4 and 5.

\section{Results}

Principal Axis Factoring (PAF)

The underlying assumptions for PAF (with direct oblimin rotation) fixed for five factors were guaranteed: $\mathrm{KMO}=.85$ and Bartlett's Test of Sphericity significant $(p<.001)$. The structure reproduced the five dimensions of personality (Table 1). There were 10 items either with the highest loadings on unintended factors (i.e., items 164 , $87,19,162,104$ and 67) or on the intended factor but with loadings less than .30 (i.e., items 1, 45, 93 and 109; grey highlights on Table 1). The total explained variance before oblimin rotation was $35.2 \%$.

PAF analysis considering the educational background produced two different structures and guaranteed underlying assumptions - significant Bartlett's Tests of Sphericity $(p<.001)$ and adequate $\mathrm{KMO}(\mathrm{KMO}=.86$ and .84 , respectively for "secondary and tertiary education" and "primary and lower secondary education"). The "secondary and tertiary education" group revealed a five factor structure with 11 items with incongruent loadings and an explained variance of $35.39 \%$. For the "primary and lower secondary education" group, the number of items with incongruent loadings was higher (18 items) and the explained variance was similar (34.48\%; Tables 8-9 Appendix).

Table 1

Principal Axis Factoring with Direct Oblimin Rotation Solutions of NEO-FFI Items

\begin{tabular}{ccccccc}
\hline & & & & Factor & & \\
\cline { 2 - 7 } Item & Communalities & $\mathrm{E}$ & $\mathrm{C}$ & $\mathrm{N}$ & $\mathrm{A}$ & $\mathrm{O}$ \\
\hline 177 & .64 & $\mathbf{. 7 5}$ & -.01 & -.15 & .17 & -.04 \\
237 & .49 & $\mathbf{. 6 8}$ & -.10 & .03 & .16 & .08 \\
147 & .52 & $\mathbf{. 5 9}$ & -.02 & -.24 & .22 & .06 \\
122 & .44 & $\mathbf{. 5 9}$ & .11 & .06 & .21 & .00 \\
107 & .35 & $\mathbf{. 4 9}$ & .03 & -.04 & -.25 & .14 \\
37 & .22 & $\mathbf{. 4 9}$ & -.06 & .00 & .04 & -.10 \\
227 & .52 & $\mathbf{. 4 4}$ & .37 & -.20 & -.13 & .14 \\
142 & .28 & $\mathbf{. 4 0}$ & .07 & -.05 & -.17 & .20 \\
164 & .28 & $\mathbf{. 3 4}$ & .21 & -.04 & .24 & -.22 \\
197 & .17 & $\mathbf{. 3 1}$ & .10 & .04 & -.12 & .17 \\
85 & .51 & .06 & $\mathbf{. 7 0}$ & -.06 & -.06 & .01 \\
110 & .45 & .10 & $\mathbf{. 6 5}$ & .01 & -.10 & .03 \\
200 & .46 & .23 & $\mathbf{. 6 0}$ & -.01 & -.16 & -.02 \\
25 & .39 & .02 & $\mathbf{. 6 0}$ & -.10 & .00 & -.06 \\
50 & .36 & .10 & $\mathbf{. 5 5}$ & -.06 & -.05 & .12 \\
55 & .34 & -.13 & $\mathbf{. 5 2}$ & -.16 & .08 & -.16 \\
135 & .30 & .04 & $\mathbf{. 5 1}$ & -.03 & .06 & .09 \\
15 & .33 & .12 & $\mathbf{. 5 1}$ & .07 & .09 & .09 \\
130 & .29 & .15 & $\mathbf{. 5 0}$ & -.14 & .10 & -.01 \\
40 & .28 & .05 & $\mathbf{. 4 8}$ & .12 & .07 & -.13
\end{tabular}


Magalhães, E., Salgueira, A., Gonzalez, A-J., Costa, J. J., Costa, M. J., Costa, P. \& Lima, M. P. (2014). NEO-FFI: Psychometric Properties of a Short Personality Inventory in Portuguese Context.

\begin{tabular}{|c|c|c|c|c|c|c|}
\hline 70 & .16 & -.12 & .42 & .04 & -.06 & .07 \\
\hline 104 & .33 & .13 & .35 & .17 & .33 & .10 \\
\hline 45 & .09 & -.05 & .19 & -.17 & .14 & -.01 \\
\hline 91 & .39 & .06 & .08 & .59 & -.18 & -.06 \\
\hline 86 & .33 & .10 & -.01 & .57 & -.11 & .05 \\
\hline 221 & .37 & .01 & -.20 & .51 & .03 & -.18 \\
\hline 71 & .44 & -.39 & -.04 & .50 & .05 & .06 \\
\hline 26 & .39 & -.02 & -.26 & .50 & -.03 & -.16 \\
\hline 11 & .33 & -.23 & .01 & .49 & .04 & -.05 \\
\hline 136 & .30 & -.11 & -.14 & .47 & -.11 & .03 \\
\hline 61 & .25 & -.06 & -.15 & .46 & .05 & .02 \\
\hline 6 & .29 & .02 & .07 & .44 & -.29 & -.05 \\
\hline 41 & .35 & -.17 & -.24 & .43 & -.07 & -.04 \\
\hline 87 & .32 & .26 & .07 & -.41 & .03 & .12 \\
\hline 76 & .19 & .07 & -.23 & .31 & -.08 & .18 \\
\hline 19 & .16 & .08 & .13 & .27 & .23 & .11 \\
\hline 1 & .08 & -.11 & .07 & .25 & .09 & .06 \\
\hline 162 & .09 & .01 & -.08 & -.23 & -.14 & .09 \\
\hline 74 & .41 & .15 & .06 & -.01 & .60 & -.07 \\
\hline 59 & .26 & .04 & -.11 & -.01 & .51 & .06 \\
\hline 39 & .32 & -.06 & .24 & .02 & .48 & -.01 \\
\hline 14 & .23 & .01 & .10 & -.09 & .44 & .02 \\
\hline 4 & .24 & .11 & -.07 & -.06 & .42 & .16 \\
\hline 229 & .24 & .04 & .24 & -.05 & .38 & -.08 \\
\hline 64 & .24 & -.03 & -.16 & -.24 & .36 & .17 \\
\hline 44 & .31 & .11 & .29 & .26 & .35 & .07 \\
\hline 67 & .16 & .03 & -.11 & -.14 & .31 & .18 \\
\hline 109 & .10 & -.04 & -.09 & .12 & .24 & -.14 \\
\hline 188 & .34 & .03 & .05 & .15 & .04 & .57 \\
\hline 23 & .37 & .18 & -.09 & -.03 & -.12 & .52 \\
\hline 128 & .26 & -.05 & .06 & .09 & .08 & .51 \\
\hline 203 & .36 & .11 & .23 & -.01 & -.13 & .51 \\
\hline 163 & .23 & -.13 & .05 & -.10 & .10 & .45 \\
\hline 28 & .25 & .11 & .06 & -.13 & .12 & .39 \\
\hline 108 & .20 & .14 & .02 & -.08 & -.13 & .36 \\
\hline 98 & .17 & .12 & .07 & .12 & .02 & .36 \\
\hline 173 & .12 & -.05 & -.01 & -.01 & .08 & .34 \\
\hline 88 & .16 & -.04 & -.11 & -.15 & -.10 & .33 \\
\hline 78 & .19 & -.11 & -.17 & -.21 & .07 & .31 \\
\hline 93 & .13 & .13 & -.10 & .16 & .10 & .26 \\
\hline envalues & & 8.10 & 4.20 & 3.37 & 3.05 & 2.38 \\
\hline Variance & & 13.50 & 7.00 & 5.62 & 5.09 & 3.97 \\
\hline
\end{tabular}

Note. Larger loadings are in bold for each component. 


\section{Confirmatory Factor Analysis (CFA)}

In order to guarantee the adequacy of exploratory and confirmatory factor analysis statistical procedures a regression imputation was performed (according to each of the personality's dimensions) in nine participants $(.7 \%$ of the total sample). The analysis revealed that such participants answered more than 30 items of the scale and their missing answers were not in a specific personality trait. Since the initial 1237 participants were divided into three subsamples (EFA, $n=619$; CFA subsample $1, n=309$; CFA subsample 2, $n=309$ ) we have explored for possible univariate (through $z$-scores $>|3.3|, p=.001$ criteria) or multivariate (through Mahalanobis distance, $p=.001$ criteria) outliers. The proportion of participants that were not considered to be uni or multivariate outliers was substantially high (90.3\% for EFA sample, $87.4 \%$ for CFA subsample 1 and $90.0 \%$ for CFA subsample 2) and the proportions of participants that were simultaneously uni or multivariate outliers was in fact very small (3.6\% for EFA sample, $4.5 \%$ for CFA subsample 1 and $3.2 \%$ for CFA subsample 2).

The skewness and kurtosis values were within the acceptable range of the normal distribution (lower than 3.0 and 8.0, respectively; Kline, 2005). Furthermore, for the EFA sample skewness values varied between -1.207 (minimum) and .565 (maximum) and kurtosis values varied between -1.094 and 2.779. Similar results were obtained for the two CFA sub samples (skewness: CFA subsample 1, between -1.376 and .670; CFA subsample 2, between -1.361 and .545; kurtosis: CFA subsample 1, between -1.135 and 3.207; CFA subsample 2, between -1.116 and 3.649). Multicolinearity diagnosis was also performed based on tolerance scores. The minimum values obtained were .362 for EFA sample, .320 for CFA subsample 1 and .353 for CFA subsample 2, meaning that there was no multicolinearity problems. Based on these results we have decided to maintain all the participants and it gave us some guarantees to proceed with the subsequent analysis.

The fit statistics/indexes obtained with CFA for each personality dimension are summarized on Table 2 . Singlemodels with "no correlated errors" ("Poor") showed poor fit indexes considering the Comparative Fit Index (CFI) and Root Mean Square Error of Aproximation (RMSEA; Hu \& Bentler, 1999; Schermelleh-Engel, Moosbrugger, $\&$ Muller, 2003). Second single-models were tested to improve these indexes including correlated errors for the items that belong to the same facet and for other items based on Modifications Indices ("Satisfactory"). The model with five dimensions showed poor fit indexes with and without correlated errors (Table 2).

Table 2

Summary of Maximum Likelihood Model Fit Statistics/Indexes

\begin{tabular}{|c|c|c|c|c|c|c|c|c|c|c|c|c|}
\hline & \multicolumn{6}{|c|}{ Sample 1} & \multicolumn{6}{|c|}{ Sample 2} \\
\hline & $\begin{array}{c}\text { Fit } \\
\text { Level }\end{array}$ & $\chi^{2}(d f)$ & $p$ & SRMR & $\mathrm{CFI}$ & $\begin{array}{c}\text { RMSEA } \\
\text { (HI90) }\end{array}$ & $\begin{array}{c}\text { Fit } \\
\text { Level }\end{array}$ & $\chi^{2}(d f)$ & $p$ & SRMR & CFI & $\begin{array}{c}\text { RMSEA } \\
\text { (HI90) }\end{array}$ \\
\hline \multirow[t]{2}{*}{ Neuroticism } & Poor & $167.870(54)$ & $<.001$ & .061 & .87 & $.083(.097)$ & Poor & $229.268(54)$ & $<.001$ & .077 & .78 & $.103(.117)$ \\
\hline & $\begin{array}{c}\text { Satisfac- } \\
\text { tory }\end{array}$ & $80.104(37)$ & $<.001$ & .045 & .95 & $.062(.080)$ & $\begin{array}{l}\text { Satis- } \\
\text { factory }\end{array}$ & $62.063(37)$ & $<.001$ & .044 & .97 & $.047(.067)$ \\
\hline \multirow[t]{2}{*}{ Extraversion } & Poor & $251.671(54)$ & $<.001$ & .082 & .77 & $.109(.123)$ & Poor & $193.886(54)$ & $<.001$ & .077 & .76 & $.092(.106)$ \\
\hline & $\begin{array}{l}\text { Satisfac- } \\
\text { tory }\end{array}$ & 71.584(39) & .001 & .044 & .96 & $.052(.071)$ & $\begin{array}{l}\text { Satis- } \\
\text { factory }\end{array}$ & $74.233(39)$ & .001 & .049 & .95 & $.054(.073)$ \\
\hline \multirow[t]{2}{*}{ Openness } & Poor & $208.998(54)$ & $<.001$ & .077 & .72 & $.097(.111)$ & Poor & $233.817(54)$ & $<.001$ & .084 & .63 & $.104(.118)$ \\
\hline & $\begin{array}{l}\text { Satisfac- } \\
\text { tory }\end{array}$ & $61.840(38)$ & .009 & .047 & .96 & $.045(.065)$ & $\begin{array}{l}\text { Satis- } \\
\text { factory }\end{array}$ & $68.203(38)$ & .006 & .048 & .95 & $.051(.070)$ \\
\hline \multirow{2}{*}{$\begin{array}{l}\text { Agreeable- } \\
\text { ness }\end{array}$} & Poor & $195.513(54)$ & $<.001$ & .072 & .77 & $.092(.106)$ & Poor & $151.610(54)$ & $<.001$ & .064 & .79 & $.077(.091)$ \\
\hline & $\begin{array}{c}\text { Satisfac- } \\
\text { tory }\end{array}$ & $72.968(41)$ & .002 & .047 & .95 & $.050(.069)$ & $\begin{array}{l}\text { Satis- } \\
\text { factory }\end{array}$ & $55.870(51)$ & .061 & .040 & .97 & $.034(.055)$ \\
\hline \multirow{2}{*}{$\begin{array}{l}\text { Conscien- } \\
\text { tiousness }\end{array}$} & Poor & $263.688(54)$ & $<.001$ & .087 & .76 & $.112(.126)$ & Poor & $245.151(54)$ & $<.001$ & .076 & .82 & $.107(.121)$ \\
\hline & $\begin{array}{l}\text { Satisfac- } \\
\text { tory }\end{array}$ & $72.941(37)$ & $<.001$ & .045 & .96 & $.056(.075)$ & $\begin{array}{l}\text { Satis- } \\
\text { factory }\end{array}$ & $85.061(37)$ & $<.001$ & .042 & .95 & $.065(.083)$ \\
\hline \multirow{2}{*}{$\begin{array}{l}\text { Global } \\
\text { Model }\end{array}$} & 1 & $3872.933(1710)$ & $<.001$ & .119 & .58 & $.064(.067)$ & 1 & $4063.038(1710)$ & $<.001$ & .114 & .53 & $.067(0.69)$ \\
\hline & 2 & $2956.805(1622)$ & $<.001$ & .085 & .74 & $.052(.055)$ & 2 & $3227.750(1622)$ & $<.001$ & .092 & .68 & $.057(.060)$ \\
\hline
\end{tabular}

Note. 1- Without correlated errors; 2 - With correlations between five factors and between the same errors to single models. 
Magalhães, E., Salgueira, A., Gonzalez, A-J., Costa, J. J., Costa, M. J., Costa, P. \& Lima, M. P. (2014). NEO-FFI: Psychometric Properties of a Short Personality Inventory in Portuguese Context.

\section{Reliability}

Cronbach's Alpha values were: Conscientiousness $=.81$, Neuroticism $=.81$, Extraversion $=.75$, Agreeableness $=.72$ and Openness $=.71$, which are similar to the ones reported for the original NEO-FFI in the USA (McCrae $\&$ Costa, 2004).
The alternative estimates of internal consistency by standardized factor loadings (corresponding to $\chi$ ) and standardized errors variances (corresponding to $\delta$ ) are presented in Tables 1-5 in Appendix. The standardized correlated errors are presented in Tables 6-7 in Appendix. The summary of reliability estimates is presented in Table 3 .

Table 3

Summary of Reliability Estimates for Samples 1 and 2

\begin{tabular}{ccccccc}
\hline \multicolumn{7}{c}{ Sample 1 } \\
& $\omega \mathrm{A}$ & $\omega \mathrm{B}$ & $\Delta \omega$ & $\omega \mathrm{A}$ & $\omega \mathrm{B}$ & $\Delta \omega$ \\
$\mathrm{N}$ & .98 & .92 & .05 & .97 & .92 & .06 \\
$\mathrm{E}$ & .97 & .90 & .07 & .97 & .84 & .13 \\
$\mathrm{O}$ & .96 & .87 & .09 & .95 & .82 & .13 \\
$\mathrm{C}$ & .98 & .92 & .06 & .99 & .92 & .06 \\
$\mathrm{~A}$ & .98 & .93 & .04 & .97 & .96 & .02 \\
\hline
\end{tabular}

\section{Factors Inter-Correlation}

Table 4 reports the inter-correlations between the five factors produced by PAF. Low, significant and positive correlations were found between: (a) Extraversion and
Openness or Conscientiousness; (b) Conscientiousness and Agreeableness. Neuroticism and Extraversion, Openness or Conscientiousness showed negative correlations. Correlations ranged from -.01 to .24 .

Table 4

Intercorrelations Matrix

\begin{tabular}{|c|c|c|c|c|}
\hline Factor & Conscientiousness & Neuroticism & Agreeableness & Openness \\
\hline Extraversion & $.212 * * *$ & $-.116^{* *}$ & .046 & $.242 * * *$ \\
\hline Conscientiousness & - & $-.085^{*}$ & $.157 * * *$ & -.006 \\
\hline Neuroticism & & - & -.042 & $-.125 * *$ \\
\hline Agreeableness & & & - & .053 \\
\hline
\end{tabular}

$* p<.05 ; * * p<.01 ; * * * p<.001$.

\section{Multivariate Analysis}

The academic qualifications diverged related to age $[t$ $(1173)=32.26, p<.001]$ : subjects with "Primary/Lower Secondary Education" ( $M=61.4)$ were significantly older than those with "Secondary/Tertiary Education" $(M=30)$. To control the effect of age on academic qualifications, a MANCOVA was performed after assuring assumptions of homogeneity of Covariance Matrices and Multicollinearity and Singularity.

Significant main effects of gender and academic qualifications on personality dimensions were found, using age as a covariant. Results indicated that females scored significantly higher on Neuroticism $[F(1,1174)=54.12$, $p<.001 ; \chi_{p}^{2}=.044,95 \%$ CI $\left.(2.67,5.01)\right]$, Conscientiousness $\left[F(1,1174)=5.00, p<.05 ; \chi_{p}^{2}=.004,95 \%\right.$ CI $(.26$, $2.27)]$ and Agreeableness $\left[F(1,1174)=14.40, p<.001 ; \chi^{2}\right.$ $=.012,95 \%$ CI $(.81,2.60)]$. Participants with "Primary Education/Lower Education" scored significantly lower on Openness $\left[F(1,1174)=46.56, p<.001 ; \chi_{\mathrm{p}}^{2}=.038,95 \%\right.$ CI $(-4.42,-1.87)]$ than those with "Secondary/Tertiary Education". In a bivariate analysis, significant, moderate and negative correlations were found between age and Extraversion $(r=-.276, p<.001)$ and Openness $(r$ $=-.450, p<.001)$. Low but significant and positive correlation was found between age and Conscientiousness $(r=.091, p<.01)$.

\section{Discussion}

The NEO- FFI is used across cultures to measure the five dimensions of personality. The present work assessed the psychometric properties of the Portuguese NEOFFI, an instrument developed with items taken from the NEO-PI-R to meet the need for a shortened measure of personality in Portugal. The results obtained with Principal Axis Factoring and Confirmatory Factor Analysis showed 
that the Portuguese NEO-FFI is largely equivalent to the original version (McCrae \& Costa, 2004) and further confirms that the five dimensions of personality are present in the Portuguese population.

Research that involves the adaptations of psychometric instruments must deal with difficulties arising from cultural and linguistic differences between the source and target languages, and with higher item factor loadings in alternative dimensions. There were six such items in the present study, probably due to the following dissimilar interpretations: (a) "I usually prefer to do things alone" (item 67) is regarded a sign of individualism associated with arrogance/ overconfidence/ pride (connected to the absence of Agreeableness instead of Extroversion); (b) "Most people I know like me" (item 164) is commonly seen as conceit (connected to Extroversion instead of Agreeableness); (c) "I'm not a cheerful optimist" (item 87, which is originally from Extroversion) and "I would rather cooperate with others than compete with them" (item 19, which is originally from Agreeableness) can be seen as a sign of distress or neuroticism (connected to Neuroticism); (d) "I would rather go my own way than be a leader of others" (item 162) can be perceived as self-centeredness with a neurotic flavor (connected to Neuroticism instead of Extroversion); (e) "I generally try to be thoughtful and considerate" (item 104) can be viewed as an indicator or self-discipline (which relates to conscientiousness (.35) instead of Agreeableness (.33). We maintain that the Portuguese NEO-FFI should not be revised strictly according to the empirical factor loadings, since the dimensions measured are broad and the losses in internal consistency do not harm the reliability of any dimension. Within the context of the original and adaptations of NEO-FFI, previous circumstances of mismatches of item loadings, the primacy was conferred to theoretical / conceptual aspects over empirical loadings (McCrae \& Costa, 2004).

Given the reported concerns on the robustness of NEO-FFI, we triangulated methods - cross-validation, reliability and inter-correlations - to study the Portuguese adaptation. We essentially found coherency between the results arising from the different methods. The values for the dimensional internal consistencies were congruent with values reported previously for other countries (McCrae \& Costa, 2004), at the acceptable (for Openness, Extraversion and Agreeableness) and robust (for Neuroticism and Conscientiousness) levels. The intercorrelations revealed by PAF between personality factors were significant and could reflect a general factor of personality as suggested by other authors (Bäckstrom, Bjorklund, \& Larsson, 2009). The construct validity of the Portuguese NEO-FFI was assessed with PAF and CFA single models that originated fit indexes above the consensus cutoff points for such circumstances (Hu \& Bentler, 1999; Schermelleh-Engel et al., 2003). The international literature on validation of NEOFFI adaptations presents different approaches of CFA (Egan et al., 2000; Gignac et al., 2007). In the present study, CFA was performed based on current evidence that suggest an alternative factorial method for testing personality structure. Based on the relative interdependence of the five personality dimensions, the recommendation is that CFA is applied to each dimension individually instead of considering the 5 dimensions of personality as a single model (Gignac et al., 2007). In fact, the application of a CFA global model failed to originate fit indexes adjusted to data above the same cutoff points. A biasing effect on the reliability by the misfit CFA model was found in our data, as reported previously by Gignac and colleagues (2007).

The validity of the Portuguese NEOFFI is corroborated by congruencies of the Portuguese NEO-FFI and NEO-PI-R (Lima, 1997) and by with international studies (McCrae \& Costa, 2004). Firstly, the study found a main effect of gender and academic qualifications on personality using age as covariate. Secondly, the study replicated the "crucial practical importance" (Hojat \& Hu, 2004, p. 243 ) of the association between academic qualifications and personality, as higher education had a positive effect on personality scores (perhaps reflecting college students' relatively stronger will for stimulating experiences and for pursuing knowledge). Thirdly, there was a female gender effect on Neuroticism, Conscientiousness and Agreeableness - in this case with small effect size estimates (Colliver, 2007; Lecroy \& Krysik, 2007). This result is theoretically plausible as the literature suggests that there are some psychosocial gender specificities, specifically, the more investment of women in nurturing than men (reflecting more agreeableness), the tendency to feel depressed or anxious more prevalent in women (higher neurotic scores), and the emphasis on social expectations of an appropriate behavior that is more prominent for females than males (Aluja et al., 2005; Costa, Terracciano, \& McCrae, 2001). Finally, the age correlated with three personality dimensions (Lima, 1997; McCrae et al., 1999), negatively for Extraversion and Openness, and higher on Conscientiousness, a recurrent finding related to the "psychosocial maturity" of the participants (McCrae et al., 1999).

In summary, the Portuguese NEO-FFI is a reliable personality measurement tool, more convenient than the NEO-PI-R. As in the original version, gains in convenience are met at the expense of loss of information concerning NEO-PI-R facets. The study's main limitation was the use of samples of convenience mostly college age, which might condition the generalizability of the results to the Portuguese population. Nevertheless, the NEO-FFI revealed the primary dimensions of personality proposed in the Five Factor Model in Portuguese subjects. This study's demonstration of the validity and reliability of the Portuguese Neo-FFI contributes to international research on personality and paves the way for future comparative and collaborative research on the FFM incorporating Portuguese participants. 
Magalhães, E., Salgueira, A., Gonzalez, A-J., Costa, J. J., Costa, M. J., Costa, P. \& Lima, M. P. (2014). NEO-FFI: Psychometric Properties of a Short Personality Inventory in Portuguese Context.

\section{References}

Aluja, A., Garcia, O., Rossier, J., \& Garcia, L. (2005). Comparison of the NEO-FFI, NEO-FFI-R and an alternative short version of the NEO-PI-R (NEO-60) in Swiss and Spanish samples. Personality and individual Differences, 38(1), 591604. doi:10.1016/j.paid.2004.05.014

Arbuckle, J. L. (2009). Amos 18 user's guide. Chicago, IL: Amos Development Corporation.

Bäckstrom, M., Bjorklund, F., \& Larsson, M. (2009). Fivefactor inventories have a major general factor related to social desirability which can be reduced by framing items neutrally. Journal of Research in Personality, 43, 335-344. doi:10.1016/j.jrp.2008.12.013

Colliver, J. (2007). Effect-size measures and research in developmental and behavioral pediatrics. Journal of Developmental \& Behavioral Pediatrics, 28(2), 145-150. doi:101097/DBP.0b013e318045beee

Costa, P., \& McCrae, R. (1989). The NEO PI manual supplement. Odessa, FL: Psychological Assessment Resources.

Costa, P., \& McCrae, R. (1992). The revised NEO PI / NEO-FFI professional manual. Odessa, FL: Psychological Assessment Resources.

Costa, P., McCrae, R., \& Dye, D. (1991). Facet scales for agreeableness and conscientiousness: A revision of the NEO Personality Inventory. Personality and Individual Differences, 12, 887-898. doi:10.1016/0191-8869(91)90177-D

Costa, P., Terracciano, A., \& McCrae, R. (2001). Gender differences in personality traits across cultures: Robust and surprising findings. Journal of Personality and Social Psychology, $81,322-331$.

Egan, V., Deary, I., \& Austin, E. (2000). The NEO-FFI: Emerging British norms and an item-level analysis sugest N, A, and C are more reliable than $\mathrm{O}$ and E. Personality and Individual Differences, 29, 907-920. doi:10.1016/S0191-8869(99)00242-1

Furham, A. F. (1997). Knowing and faking one's five-factor personality score. Journal of Personality Assessment, 69(1), 229-243.

Gignac, G., Bates, T., \& Jang, K. (2007). Implications relevant to CFA model misfit, reliability, and five-factor model as measured by the NEO-FFI. Personality and Individual Differences, 43, 1051-1062. doi:10.1016/j.paid.2007.02.024

Hojat, M., \& Xu, G. (2004). A visitor's guide to effect sizes: Statistical significance versus practical (clinical) importance of research findings. Advances in Health Sciences Education: Theory and Practice, 9(3), 241-249.

Hu, L., \& Bentler, P. (1999). Cutoff criteria for fit indexes in covariance structure analysis: Conventional criteria versus new alternatives. Structural Equation Modelling, 6(1), 1-55. doi:10.1080/10705519909540118

Institute of National Statistics. (2010). Indicators on education, training and learning by gender and age. Retrieved from $\mathrm{http} / / / \mathrm{www}$.ine.pt/xportal/xmain?xpid=INE\&xpgid=ine_main

Kline, R. (2005). Principles and practice of structural equations modelling ( $2^{\text {nd }}$ ed.). London: Guilford Press.

Korner, A., Geyer, M., Roth, M., Drapeau, M., Schmutzer, G., Albani, C., ... Brahler, E. (2008). Personality assessment with the NEO-Five-Factor Inventory: The 30-Item-Short-Version (NEO-FFI-30). Psychotherapie Psychosomatik Medizinische Psychologie, 58(6), 238-245.

Lecroy, C., \& Krysik, J. (2007). Understanding and interpreting effect size measures. Social Work Research, 31(4), 243-248.
Lima, M. P. (1997). NEO-PI-R contextos teóricos e psicométricos. "OCEAN" ou "iceberg"? (Unpublished doctoral dissertation). Faculty of Psychology and Educational Sciences, University of Coimbra, Portugal.

Lucas, R., \& Donnellan, M. (2009). Age differences in personality: Evidence from a nationally representative Australian sample. Developmental Psychology, 45(5), 13531363. doi:10.1037/a0013914

McCrae, R., \& Costa, P. (2004). A contemplated revision of the NEO Five-Factor Inventory. Personality and Individual Differences, 36(3), 587-596. doi:10.1016/S01918869(03)00118-1

McCrae, R., Costa, P., Del Pilar, G., Rolland, J., \& Parker, W. (1998). Cross-cultural assessment of the FiveFactor Model: The Revised NEO Personality Inventory. Journal of Cross-Cultural Psychology, 29, 171-188. doi:10.1177/0022022198291009

McCrae, R., Costa, P., Lima, M. P., Simões, A., Ostendorf, F., Angleitner, A., ...Piedmont, R. (1999). Age differences in personality across the adult life span: Parallels in five cultures. Developmental Psychology, 35(2), 466-477.

McCrae, R., Terracciano, A., \& Personality Profiles of Cultures Project. (2005). Universal features of personality traits from the observer's perspective: Data from 50 cultures. Journal of Personality and Social Psychology, 88, 547-561.

Muck, P., Hell, B., \& Gosling, S. (2007). Construct validation of a short five-factor model instrument. A self-peer study on the German adaptation of the Ten-Item Personality Inventory (TIPI-G). European Journal of Psychological Assessment, 23(3), 166-175. doi:10.1027/1015-5759.23.3.166

Rolland, J., Parker, W., \& Stumpf, H. (1998). A psychometric examination of the French translations of the NEO-PI-R and NEO-FFI. Journal of Personality Assessment, 71(2), 269-291. doi:10.1207/s15327752jpa7102 13

Schermelleh-Engel, K., Moosbrugger, H., \& Muller, H. (2003). Evaluating the fit of structural equation models: Tests of significance and descriptive goodness-of-fit measures. Methods of Psychological Research Online, 8(2), 23-74.

Van de Vijver, F. J. R., \& Hambleton, R. K. (1996). Translating tests: Some practical guidelines. European Psychologist, 1, 89-99. doi:10.1027/1016-9040.1.2.89 
Psicologia: Reflexão e Crítica, 27(4), 642-657.

\section{Appendix}

Table 1

Completely Standardized MLE Parameter Estimates for Poor and Satisfactory Fitting Single-Factor Models: Neuroticism

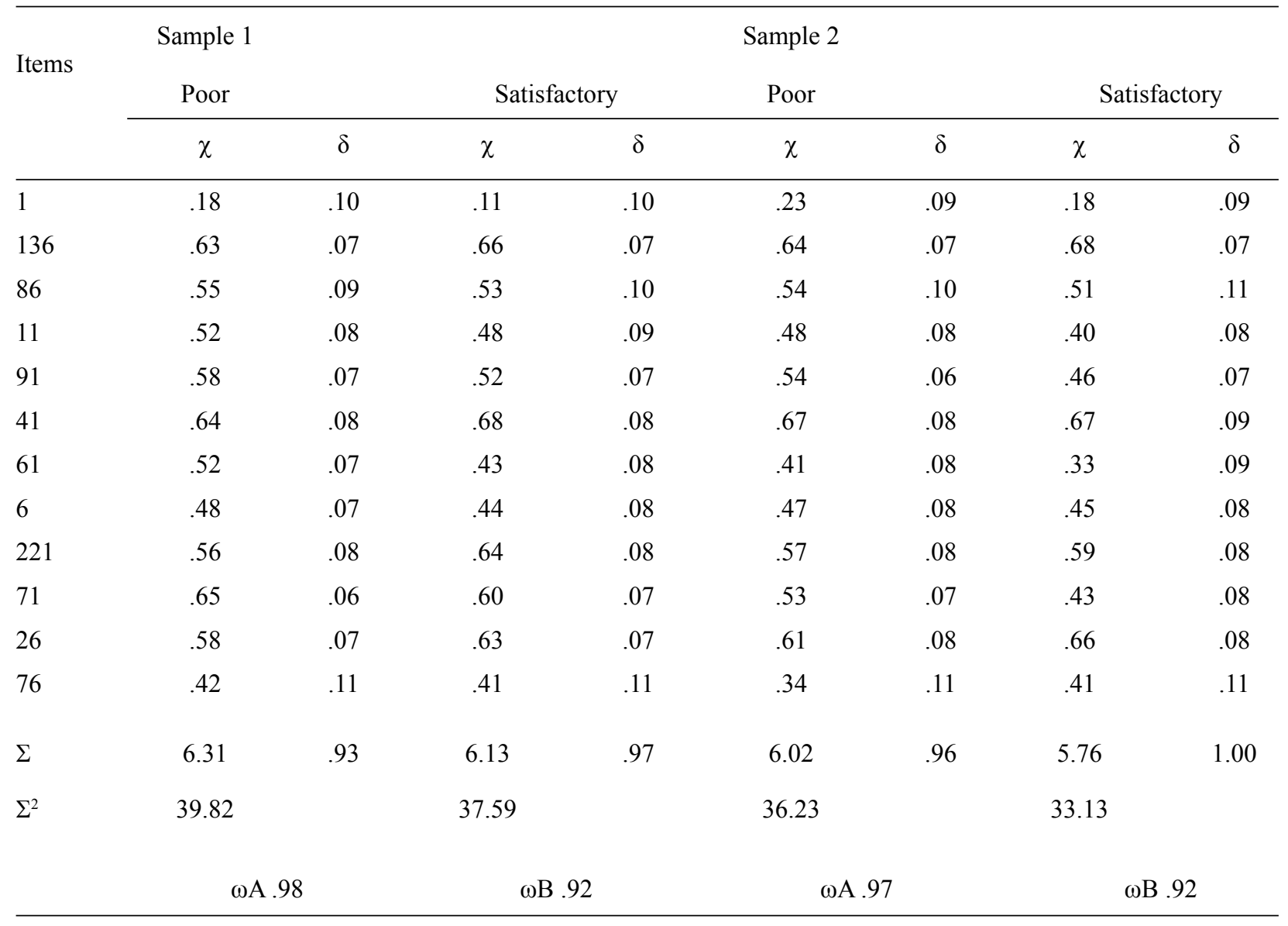

Note. All factor loadings were statistically significant $(p<.001) ; \chi=$ standardized factor loadings; $\delta=$ standardized errors variances; $\Sigma=$ Sum; $\Sigma^{2}=$ Sum Square; $\omega \mathrm{A}=$ reliability estimates for poor model; $\omega \mathrm{B}=$ reliability estimates for satisfactory model.

Table 2

Completely Standardized MLE Parameter Estimates for Poor and Satisfactory Fitting Single-Factor Models: Extraversion

\begin{tabular}{|c|c|c|c|c|c|c|c|c|}
\hline \multirow{3}{*}{ Items } & \multirow{2}{*}{\multicolumn{2}{|c|}{$\begin{array}{c}\text { Sample } 1 \\
\text { Poor }\end{array}$}} & \multicolumn{6}{|c|}{ Sample 2} \\
\hline & & & \multicolumn{2}{|c|}{ Satisfactory } & \multicolumn{2}{|c|}{ Poor } & \multicolumn{2}{|c|}{ Satisfactory } \\
\hline & $\chi$ & $\delta$ & $\chi$ & $\delta$ & $\chi$ & $\delta$ & $\chi$ & $\delta$ \\
\hline 37 & .42 & .07 & .46 & .07 & .43 & .08 & .48 & .08 \\
\hline 237 & .65 & .06 & .49 & .08 & .65 & .05 & .52 & .06 \\
\hline 147 & .76 & .05 & .55 & .07 & .57 & .07 & .25 & .09 \\
\hline 122 & .53 & .04 & .59 & .04 & .52 & .05 & .61 & .05 \\
\hline 142 & .33 & .06 & .43 & .06 & .35 & .07 & .50 & .07 \\
\hline 67 & .15 & .09 & .08 & .09 & .07 & .08 & .01 & .08 \\
\hline 107 & .41 & .07 & .49 & .07 & .39 & .07 & .39 & .08 \\
\hline 177 & .86 & .03 & .72 & .05 & .80 & .04 & .63 & .05 \\
\hline 87 & .42 & .09 & .22 & .10 & .39 & .09 & .18 & .10 \\
\hline
\end{tabular}


Magalhães, E., Salgueira, A., Gonzalez, A-J., Costa, J. J., Costa, M. J., Costa, P. \& Lima, M. P. (2014). NEO-FFI: Psychometric Properties of a Short Personality Inventory in Portuguese Context.

$\begin{array}{lcccccccc}197 & .19 & .07 & .23 & .07 & .21 & .07 & .15 & .07 \\ 227 & .59 & .05 & .68 & .05 & .42 & .06 & .50 & .06 \\ 162 & .08 & .09 & .08 & .09 & .03 & .07 & -.01 & .07 \\ \Sigma & 5.39 & .75 & 5.01 & .84 & 4.84 & .79 & 4.22 & .86 \\ \Sigma^{2} & 29.07 & & 25.07 & & 23.41 & & 17.81 & \end{array}$
$\omega \mathrm{A} .97$
$\omega \mathrm{B} .90$
$\omega \mathrm{A} .97$
$\omega \mathrm{B} .84$

Note. All factor loadings were statistically significant $(p<.001) ; \chi=$ standardized factor loadings; $\delta=$ standardized errors variances; $\Sigma=$ Sum; $\Sigma^{2}=$ Sum Square; $\omega \mathrm{A}=$ reliability estimates for poor model; $\omega \mathrm{B}=$ reliability estimates for satisfactory model.

Table 3

Completely Standardized MLE Parameter Estimates for Poor and Satisfactory Fitting Single-Factor Models: Openness to Experience

\begin{tabular}{|c|c|c|c|c|c|c|c|c|}
\hline \multirow{3}{*}{ Items } & \multirow{2}{*}{\multicolumn{2}{|c|}{$\begin{array}{c}\text { Sample } 1 \\
\text { Poor }\end{array}$}} & \multicolumn{6}{|c|}{ Sample 2} \\
\hline & & & \multicolumn{2}{|c|}{ Satisfactory } & \multicolumn{2}{|l|}{ Poor } & \multicolumn{2}{|c|}{ Satisfactory } \\
\hline & $\chi$ & $\delta$ & $\chi$ & $\delta$ & $\chi$ & $\delta$ & $\chi$ & $\delta$ \\
\hline 93 & .36 & .09 & .34 & .09 & .23 & .10 & .28 & .10 \\
\hline 78 & .11 & .09 & .17 & .09 & .18 & .07 & .27 & .07 \\
\hline 98 & .45 & .06 & .35 & .06 & .47 & .05 & .27 & .06 \\
\hline 28 & .46 & .08 & .58 & .09 & .32 & .09 & .48 & .10 \\
\hline 128 & .59 & .09 & .44 & .11 & .50 & .09 & .21 & .11 \\
\hline 108 & .36 & .10 & .33 & .11 & .27 & .11 & .19 & .12 \\
\hline 163 & .43 & .07 & .52 & .07 & .37 & .08 & .55 & .08 \\
\hline 88 & .24 & .12 & .29 & .12 & .22 & .13 & .31 & .13 \\
\hline 188 & .63 & .08 & .44 & .10 & .67 & .08 & .38 & .09 \\
\hline 173 & .29 & .09 & .37 & .09 & .35 & .09 & .45 & .10 \\
\hline 203 & .54 & .05 & .49 & .06 & .51 & .06 & .32 & .07 \\
\hline 23 & .57 & .07 & .68 & .11 & .50 & .08 & .71 & .15 \\
\hline$\Sigma$ & 5.02 & 1.01 & 4.99 & 1.09 & 4.60 & 1.03 & 4.41 & 1.15 \\
\hline$\Sigma^{2}$ & 25.18 & & 24.94 & & 21.18 & & 19.41 & \\
\hline
\end{tabular}

$\omega \mathrm{A} .96$

$\omega \mathrm{B} .87$

$\omega \mathrm{A} .95$

$\omega \mathrm{B} .82$

Note. All factor loadings were statistically significant $(p<.001) ; \chi=$ standardized factor loadings; $\delta=$ standardized errors variances; $\Sigma=$ Sum; $\Sigma^{2}=$ Sum Square; $\omega \mathrm{A}=$ reliability estimates for poor model; $\omega \mathrm{B}=$ reliability estimates for satisfactory model. 
Psicologia: Reflexão e Crítica, 27(4), 642-657.

Table 4

Completely Standardized MLE Parameter Estimates for Poor and Satisfactory Fitting Single-Factor Models: Agreeableness

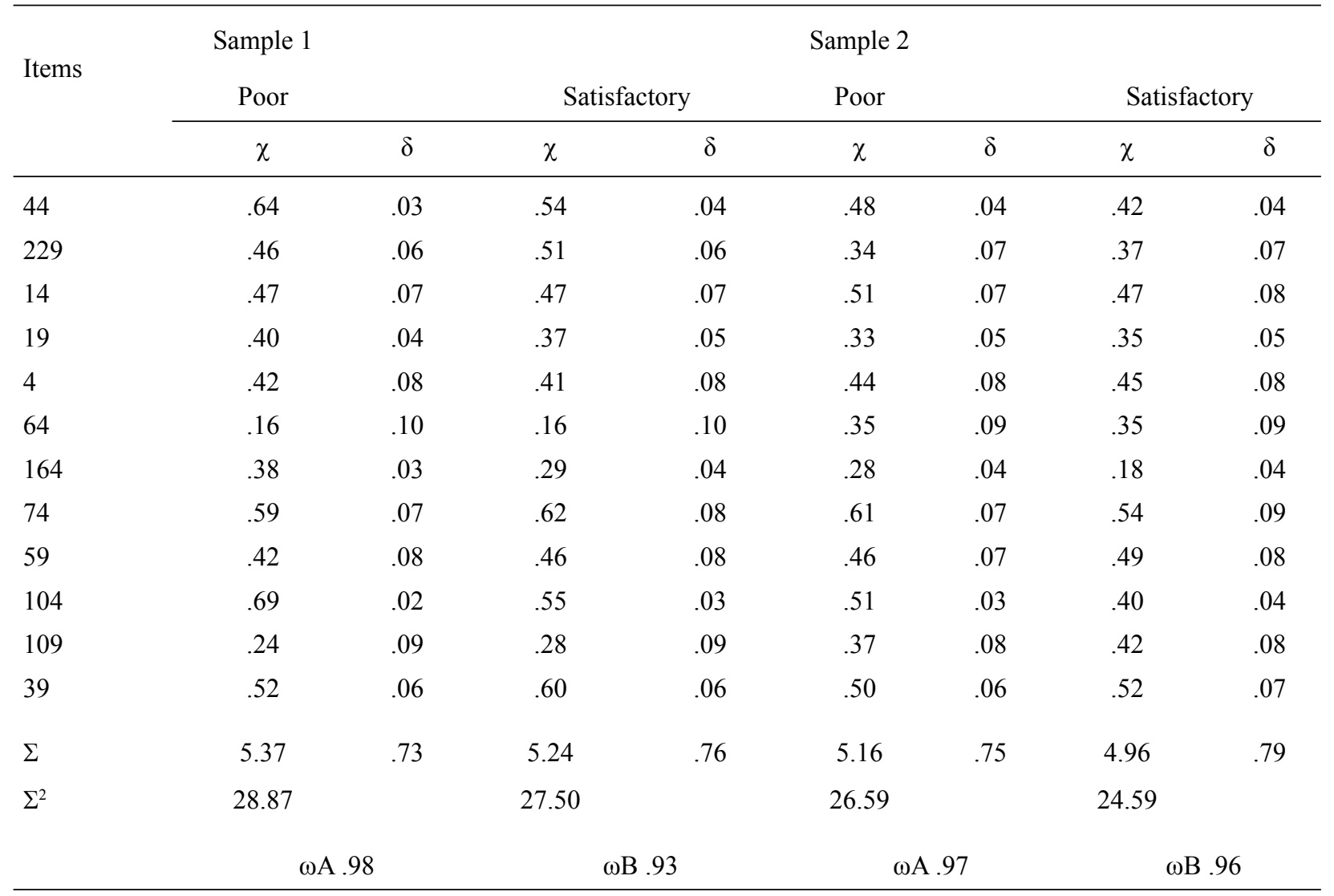

Note. All factor loadings were statistically significant $(p<.001) ; \chi=$ standardized factor loadings; $\delta=$ standardized errors variances; $\Sigma=$ Sum; $\Sigma^{2}=$ Sum Square; $\omega \mathrm{A}=$ reliability estimates for poor model; $\omega \mathrm{B}=$ reliability estimates for satisfactory model.

Table 5

Completely Standardized MLE Parameter Estimates for Poor and Satisfactory Fitting Single-Factor Models: Conscientiousness

\begin{tabular}{|c|c|c|c|c|c|c|c|c|}
\hline \multirow{3}{*}{ Items } & \multirow{2}{*}{\multicolumn{2}{|c|}{$\begin{array}{c}\text { Sample } 1 \\
\text { Poor }\end{array}$}} & \multicolumn{6}{|c|}{ Sample 2} \\
\hline & & & \multicolumn{2}{|c|}{ Satisfactory } & \multicolumn{2}{|c|}{ Poor } & \multicolumn{2}{|c|}{ Satisfactory } \\
\hline & $\chi$ & $\delta$ & $\chi$ & $\delta$ & $\chi$ & $\delta$ & $\chi$ & $\delta$ \\
\hline 40 & .42 & .05 & .38 & .06 & .51 & .06 & .47 & .06 \\
\hline 25 & .59 & .05 & .56 & .06 & .65 & .05 & .62 & .06 \\
\hline 70 & .40 & .08 & .34 & .08 & .49 & .08 & .42 & .09 \\
\hline 15 & .53 & .03 & .56 & .03 & .63 & .02 & .68 & .02 \\
\hline 50 & .61 & .04 & .59 & .04 & .54 & .05 & .53 & .05 \\
\hline 55 & .35 & .10 & .23 & .10 & .46 & .09 & .37 & .10 \\
\hline 110 & .57 & .04 & .56 & .04 & .64 & .04 & .64 & .04 \\
\hline 135 & .61 & .02 & .62 & .03 & .53 & .03 & .54 & .03 \\
\hline 45 & .21 & .10 & .18 & .10 & .27 & .08 & .25 & .09 \\
\hline 85 & .72 & .03 & .72 & .03 & .72 & .03 & .73 & .03 \\
\hline
\end{tabular}


Magalhães, E., Salgueira, A., Gonzalez, A-J., Costa, J. J., Costa, M. J., Costa, P. \& Lima, M. P. (2014). NEO-FFI: Psychometric Properties of a Short Personality Inventory in Portuguese Context.

$\begin{array}{lllllllll}130 & .49 & .07 & .40 & .07 & .50 & .07 & .39 & .07 \\ 200 & .60 & .04 & .60 & .04 & .66 & .04 & .68 & .04 \\ \Sigma & 6.08 & .64 & 5.73 & .68 & 6.60 & .64 & 6.31 & .68 \\ \Sigma^{2} & 36.93 & & 32.84 & & 43.57 & & 39.84\end{array}$
$\omega \mathrm{A} .98$
$\omega \mathrm{B} .93$
$\omega \mathrm{A} .97$
$\omega \mathrm{B} .96$

Note. All factor loadings were statistically significant $(p<.001) ; \chi=$ standardized factor loadings; $\delta=$ standardized errors variances; $\Sigma=$ Sum $; \omega \mathrm{A}=$ reliability estimates for poor model $\omega \mathrm{B}=$ reliability estimates for satisfactory model.

Table 6

Completely Standardized MLE Residual Correlations for Satisfactory Fitting Single-Factor Models: Openness, Extraversion and Conscientiousness

\begin{tabular}{|c|c|c|c|c|c|c|c|c|c|c|c|c|c|c|c|c|c|}
\hline \multicolumn{6}{|c|}{ Openness } & \multicolumn{6}{|c|}{ Extraversion } & \multicolumn{6}{|c|}{ Conscientiousness } \\
\hline \multicolumn{3}{|c|}{ Correlated items } & \multicolumn{3}{|c|}{ Sample } & \multicolumn{3}{|c|}{ Correlated items } & \multicolumn{3}{|c|}{ Sample } & \multicolumn{3}{|c|}{ Correlated items } & \multicolumn{3}{|c|}{ Sample } \\
\hline & & & 1 & 2 & |dif $\mid$ & & & & 1 & 2 & |dif $\mid$ & & & & 1 & 2 & $\mid$ dif $\mid$ \\
\hline 98 & $<-->$ & 128 & .09 & .16 & .08 & 37 & $<-->$ & 67 & .11 & .07 & .04 & 40 & $<-->$ & 130 & .194 & .285 & .09 \\
\hline 128 & $<-->$ & 188 & .44 & .53 & .09 & 107 & $<-->$ & 197 & .09 & .14 & .05 & 70 & $<-->$ & 130 & .408 & .402 & .01 \\
\hline 78 & $<-->$ & 108 & .07 & .05 & .02 & 107 & $<-->$ & 227 & .08 & .21 & .12 & 40 & $<-->$ & 70 & .251 & .235 & .02 \\
\hline 173 & $<-->$ & 23 & -.10 & -.15 & .04 & 197 & $<-->$ & 227 & .09 & .13 & .04 & 25 & $<-->$ & 55 & .185 & .22 & .04 \\
\hline 173 & $<-->$ & 203 & -.15 & .11 & .27 & 147 & $<-->$ & 87 & .37 & .35 & .02 & 15 & $<-->$ & 135 & .242 & -.09 & .33 \\
\hline 203 & $<-->$ & 23 & .13 & .22 & .10 & 177 & $<-->$ & 87 & .30 & .25 & .05 & 50 & $<-->$ & 110 & .112 & .174 & .06 \\
\hline 28 & $<-->$ & 88 & .13 & .17 & .04 & 87 & $<-->$ & 237 & .21 & .19 & .03 & 135 & $<-->$ & 45 & .017 & .092 & .08 \\
\hline 98 & $<-->$ & 188 & .33 & .27 & .06 & 147 & $<-->$ & 177 & .49 & .49 & .00 & 15 & $<-->$ & 45 & -.003 & -.067 & .06 \\
\hline 78 & $<-->$ & 88 & .21 & .10 & .12 & 147 & $<-->$ & 237 & .37 & .36 & .01 & 110 & $<-->$ & 200 & .117 & .183 & .07 \\
\hline 163 & $<-->$ & 23 & -.32 & -.40 & .08 & 177 & $<-->$ & 237 & .36 & .28 & .08 & 50 & $<-->$ & 200 & .126 & .012 & .11 \\
\hline 108 & $<-->$ & 203 & .14 & .25 & .11 & 87 & $<-->$ & 162 & .21 & .10 & .11 & 25 & $<-->$ & 85 & .072 & .024 & .05 \\
\hline 98 & $<-->$ & 203 & .03 & .19 & .16 & 147 & $<-->$ & 67 & .17 & .08 & .09 & 55 & $<-->$ & 85 & .185 & .083 & .10 \\
\hline 28 & $<-->$ & 23 & -.11 & -.35 & .24 & 37 & $<-->$ & 122 & .31 & .18 & .13 & 55 & $<-->$ & 130 & .289 & .258 & .03 \\
\hline 78 & $<-->$ & 98 & -.01 & -.14 & .13 & 107 & $<-->$ & 87 & .23 & .04 & .19 & 70 & $<-->$ & 55 & .206 & .199 & .01 \\
\hline 108 & $<-->$ & 88 & .12 & .14 & .02 & 67 & $<-->$ & 107 & -.23 & -.05 & .19 & 70 & $<-->$ & 15 & -.173 & -.055 & .12 \\
\hline \multirow[t]{4}{*}{98} & $<-->$ & 28 & -.18 & .07 & .24 & & & & & & & 45 & $<-->$ & 130 & .175 & .152 & .02 \\
\hline & & & & & & & & & & & & 25 & $<-->$ & 130 & .15 & .189 & .04 \\
\hline & & $\Sigma$ & .83 & 1.24 & .11 & & & $\Sigma$ & 3.17 & 2.80 & .08 & & & $\Sigma$ & 2.55 & 2.30 & .07 \\
\hline & & ${ }^{2} \Sigma$ & 1.66 & 2.47 & & & & ${ }^{2} \Sigma$ & 6.34 & 5.60 & & & & ${ }^{2} \Sigma$ & 5.11 & 4.59 & \\
\hline
\end{tabular}

Note. $\Sigma=$ Sum; $\mid$ dif $\mid=$ difference between 1 and 2 . 
Psicologia: Reflexão e Crítica, 27(4), 642-657.

Table 7

Completely Standardized MLE Residual Correlations for Satisfactory Fitting Single-Factor Models: Neuroticism, Agreeableness

\begin{tabular}{|c|c|c|c|c|c|c|c|c|c|c|c|}
\hline \multicolumn{6}{|c|}{ Neuroticism } & \multicolumn{6}{|c|}{ Agreeableness } \\
\hline \multicolumn{3}{|c|}{ Correlated items } & \multicolumn{2}{|c|}{ Sample } & \multirow[b]{2}{*}{$|\operatorname{dif}|$} & \multicolumn{3}{|c|}{ Correlated items } & \multicolumn{2}{|c|}{ Sample } & \multirow[b]{2}{*}{$|\operatorname{dif}|$} \\
\hline & & & 1 & 2 & & & & & 1 & 2 & \\
\hline 1 & $<-->$ & 61 & .16 & .14 & .02 & 4 & $<-->$ & 64 & .41 & .18 & .23 \\
\hline 1 & $<-->$ & 91 & .15 & .10 & .04 & 44 & $<-->$ & 14 & -.05 & -.12 & .08 \\
\hline 91 & $<-->$ & 61 & .15 & .08 & .07 & 14 & $<-->$ & 74 & .11 & .25 & .14 \\
\hline 11 & $<-->$ & 41 & .05 & .06 & .01 & 14 & $<-->$ & 104 & .03 & -.01 & .04 \\
\hline 11 & $<-->$ & 71 & .25 & .48 & .23 & 14 & $<-->$ & 164 & .11 & .12 & .01 \\
\hline 11 & $<-->$ & 221 & -.22 & -.11 & .11 & 44 & $<-->$ & 74 & -.06 & .00 & .06 \\
\hline 41 & $<-->$ & 71 & -.04 & .07 & .11 & 44 & $<-->$ & 104 & .44 & .40 & .05 \\
\hline 41 & $<-->$ & 221 & -.13 & .08 & .20 & 44 & $<-->$ & 164 & .12 & .18 & .06 \\
\hline 221 & $<-->$ & 71 & -.08 & .02 & .11 & 19 & $<-->$ & 109 & -.03 & -.03 & .00 \\
\hline 6 & $<-->$ & 76 & .01 & -.01 & .02 & 164 & $<-->$ & 104 & .21 & .16 & .05 \\
\hline 11 & $<-->$ & 26 & -.09 & -.01 & .08 & 74 & $<-->$ & 104 & .00 & .11 & .11 \\
\hline 11 & $<-->$ & 91 & .15 & .30 & .15 & 229 & $<-->$ & 19 & -.02 & -.02 & .01 \\
\hline 6 & $<-->$ & 76 & .07 & -.18 & .25 & 229 & $<-->$ & 109 & -.09 & -.10 & .01 \\
\hline 11 & $<-->$ & 76 & -.07 & -.17 & .10 & & & & & & \\
\hline 11 & $<-->$ & 61 & .12 & .25 & .13 & & & & & & \\
\hline 61 & $<-->$ & 71 & .26 & .20 & .07 & & & & & & \\
\hline \multirow[t]{3}{*}{91} & $<-->$ & 6 & .18 & .16 & .03 & & & & & & \\
\hline & & $\Sigma$ & .93 & 1.48 & .10 & & & $\Sigma$ & 1.18 & 1.11 & .07 \\
\hline & & ${ }^{2} \Sigma$ & 1.86 & 2.95 & & & & ${ }^{2} \Sigma$ & 2.36 & 2.23 & \\
\hline
\end{tabular}

Note. $\Sigma=$ Sum; $|\operatorname{dif}|=$ difference between 1 and 2 .

Table 8

Principal Axis Factors with Direct Oblimin Rotation Solutions of NEO-FFI Items for Secondary and Tertiary Education

\begin{tabular}{ccccccc}
\hline & \multicolumn{7}{c}{ Factor } \\
\cline { 2 - 7 } Item & Communalities & $\mathrm{N}$ & $\mathrm{C}$ & $\mathrm{E}$ & $\mathrm{A}$ & $\mathrm{O}$ \\
\hline & .47 & $\mathbf{- . 6 5}$ & .12 & .03 & .22 & .04 \\
81 & .39 & $\mathbf{- . 6 3}$ & .10 & .01 & -.02 & -.01 \\
46 & .46 & $\mathbf{- . 5 9}$ & -.17 & -.16 & .06 & .02 \\
136 & .42 & $\mathbf{- . 5 8}$ & -.14 & -.14 & -.08 & -.03 \\
26 & .43 & $\mathbf{- . 5 6}$ & -.26 & .00 & -.01 & -.08 \\
221 & .42 & $\mathbf{- . 5 5}$ & -.23 & -.05 & -.06 & -.10 \\
61 & .30 & $\mathbf{- . 5 3}$ & -.02 & -.07 & -.08 & .05 \\
71 & .48 & $\mathbf{- . 5 3}$ & -.01 & -.40 & .01 & .11 \\
11 & .38 & $\mathbf{- . 4 8}$ & .03 & -.34 & .02 & .13
\end{tabular}


Magalhães, E., Salgueira, A., Gonzalez, A-J., Costa, J. J., Costa, M. J., Costa, P. \& Lima, M. P. (2014). NEO-FFI: Psychometric Properties of a Short Personality Inventory in Portuguese Context.

\begin{tabular}{|c|c|c|c|c|c|c|}
\hline 87 & .33 & .46 & .00 & .25 & -.02 & .09 \\
\hline 6 & .25 & -.45 & .03 & .01 & .23 & .06 \\
\hline 76 & .20 & -.41 & -.14 & .13 & -.01 & .01 \\
\hline 1 & .16 & -.37 & .17 & -.03 & -.07 & -.02 \\
\hline 45 & .12 & .29 & .16 & -.05 & -.06 & .05 \\
\hline 162 & .06 & .17 & .06 & -.01 & .16 & .02 \\
\hline 78 & .05 & .16 & -.11 & -.10 & -.03 & .11 \\
\hline 85 & .42 & .06 & .63 & .06 & .02 & -.06 \\
\hline 110 & .43 & -.11 & .63 & .15 & .01 & .00 \\
\hline 25 & .39 & .12 & .61 & -.06 & .04 & .01 \\
\hline 200 & .39 & -.09 & .59 & .14 & .11 & .03 \\
\hline 130 & .39 & .16 & .57 & -.19 & -.08 & -.08 \\
\hline 70 & .32 & .01 & .56 & -.10 & -.02 & -.04 \\
\hline 50 & .37 & .02 & .56 & .17 & .04 & .01 \\
\hline 55 & .36 & .22 & .50 & -.21 & -.13 & .01 \\
\hline 15 & .31 & -.04 & .49 & .14 & -.10 & .10 \\
\hline 40 & .27 & -.08 & .49 & .01 & -.11 & -.10 \\
\hline 135 & .25 & .02 & .46 & .02 & .00 & .15 \\
\hline 177 & .62 & .19 & .00 & .71 & -.19 & -.04 \\
\hline 147 & .52 & .26 & .00 & .61 & -.20 & -.04 \\
\hline 237 & .42 & .07 & -.11 & .61 & -.13 & .07 \\
\hline 122 & .42 & -.02 & .07 & .59 & -.17 & .07 \\
\hline 107 & .32 & .03 & .09 & .49 & .19 & .13 \\
\hline 227 & .44 & .15 & .34 & .47 & .13 & .09 \\
\hline 37 & .22 & -.03 & -.10 & .47 & -.09 & -.05 \\
\hline 142 & .26 & .01 & .08 & .43 & .15 & .15 \\
\hline 197 & .14 & -.13 & .10 & .32 & .05 & .09 \\
\hline 164 & .17 & .11 & .11 & .29 & -.19 & -.07 \\
\hline 74 & .38 & .01 & .07 & .14 & -.58 & .02 \\
\hline 59 & .31 & .08 & -.05 & .05 & -.55 & .01 \\
\hline 4 & .32 & .10 & -.07 & .11 & -.52 & .10 \\
\hline 39 & .28 & -.03 & .11 & -.08 & -.51 & .01 \\
\hline 44 & .28 & -.19 & .20 & .03 & -.42 & .13 \\
\hline 104 & .30 & -.14 & .26 & .05 & -.42 & .14 \\
\hline 64 & .22 & .27 & -.10 & .01 &.- .38 & .02 \\
\hline 67 & .16 & .05 & -.12 & .11 & -.37 & .01 \\
\hline 229 & .21 & .14 & .20 & -.03 & -.36 & -.09 \\
\hline 14 & .20 & .21 & .08 & .06 & -.36 & .02 \\
\hline 109 & .15 & -.12 & -.06 & -.14 & -.34 & .01 \\
\hline 19 & .17 & -.25 & .10 & .06 & -.30 & .07 \\
\hline 188 & .50 & -.15 & -.01 & -.06 & -.09 & .70 \\
\hline 128 & .40 & -.07 & .02 & -.09 & -.12 & .62 \\
\hline 98 & .30 & -.03 & -.04 & .04 & -.05 & .53 \\
\hline
\end{tabular}


Psicologia: Reflexão e Crítica, 27(4), 642-657.

\begin{tabular}{ccccccc}
23 & .29 & -.04 & -.08 & .16 & .16 & $\mathbf{. 4 7}$ \\
203 & .33 & .05 & .23 & .13 & .18 & $\mathbf{. 4 5}$ \\
173 & .15 & -.02 & -.01 & .03 & -.05 & $\mathbf{. 3 8}$ \\
163 & .13 & .11 & .11 & -.10 & -.12 &. $\mathbf{2 8}$ \\
108 & .15 & .13 & -.03 & .15 & .15 &. $\mathbf{2 8}$ \\
28 & .14 & .15 & .03 & .07 & -.14 &. $\mathbf{2 7}$ \\
93 & .13 & -.14 & -.19 & .11 & -.11 & .22 \\
88 & .09 & .13 & -.09 & -.08 & .16 &. $\mathbf{2 0}$ \\
igenvalues & & 7.57 & 4.12 & 3.76 & 3.26 & 2.53 \\
\% Variance & & 12.61 & 6.87 & 6.27 & 5.43 & 4.22 \\
\hline
\end{tabular}

Note. Larger loadings are in bold for each component. Grey highlights the expected factor of each item.

Table 9

Principal Axis Factors with Direct Oblimin Rotation Solutions of NEO-FFI Items for Primary and Lower Secondary Education

\begin{tabular}{|c|c|c|c|c|c|c|}
\hline \multirow{2}{*}{ Item } & & \multicolumn{5}{|c|}{ Factor } \\
\hline & Communalities & $\mathrm{C}$ & $\mathrm{N}$ & A & $\mathrm{E}$ & $\mathrm{O}$ \\
\hline 85 & .62 & .67 & .02 & -.04 & .20 & .14 \\
\hline 200 & .53 & .59 & .12 & -.13 & .20 & .17 \\
\hline 110 & .45 & .57 & .02 & -.16 & .18 & .10 \\
\hline 25 & .39 & .56 & -.04 & -.02 & .14 & .04 \\
\hline 50 & .42 & .54 & -.04 & -.20 & .11 & .21 \\
\hline 130 & .40 & .52 & -.21 & .23 & -.15 & -.03 \\
\hline 135 & .43 & .51 & .11 & .12 & .14 & .19 \\
\hline 15 & .41 & .50 & .20 & .07 & .13 & .19 \\
\hline 40 & .29 & .49 & .18 & .08 & .03 & -.03 \\
\hline 55 & .26 & .44 & -.22 & .04 & .01 & -.14 \\
\hline 70 & .14 & .36 & -.06 & .08 & -.16 & .00 \\
\hline 76 & .21 & -.34 & .28 & -.06 & .05 & .08 \\
\hline 45 & .19 & .24 & -.21 & .24 & -.01 & -.09 \\
\hline 91 & .31 & .01 & .54 & -.04 & .04 & -.06 \\
\hline 86 & .29 & -.06 & .51 & -.08 & .06 & .08 \\
\hline 136 & .35 & -.16 & .51 & -.10 & -.12 & .15 \\
\hline 87 & .34 & .05 & -.51 & .05 & .23 & .00 \\
\hline 26 & .35 & -.23 & .47 & .02 & -.08 & -.13 \\
\hline 6 & .26 & -.03 & .44 & -.20 & -.06 & .02 \\
\hline 221 & .31 & -.26 & .41 & .00 & .01 & -.19 \\
\hline 41 & .28 & -.32 & .36 & -.05 & -.10 & .03 \\
\hline 64 & .21 & -.06 & -.33 & .23 & -.15 & .07 \\
\hline 67 & .13 & -.13 & -.31 & .11 & -.02 & .07 \\
\hline 162 & .11 & -.10 & -.31 & -.14 & .01 & -.05 \\
\hline 11 & .17 & -.07 & .29 & .12 & -.22 & -.05 \\
\hline
\end{tabular}


Magalhães, E., Salgueira, A., Gonzalez, A-J., Costa, J. J., Costa, M. J., Costa, P. \& Lima, M. P. (2014). NEO-FFI: Psychometric Properties of a Short Personality Inventory in Portuguese Context.

\begin{tabular}{|c|c|c|c|c|c|c|}
\hline 19 & .21 & .16 & .27 & .25 & .14 & .13 \\
\hline 88 & .13 & -.22 & -.27 & -.04 & -.03 & .05 \\
\hline 61 & .16 & -.16 & .25 & .13 & -.16 & -.11 \\
\hline 78 & .14 & -.23 & -.25 & .06 & -.08 & .14 \\
\hline 173 & .08 & -.07 & -.17 & .15 & -.03 & .13 \\
\hline 74 & .38 & .09 & -.09 & .56 & .16 & -.06 \\
\hline 14 & .35 & .10 & -.13 & .52 & .02 & .06 \\
\hline 59 & .25 & -.21 & -.08 & .47 & .06 & .03 \\
\hline 39 & .36 & .30 & -.06 & .46 & -.01 & .04 \\
\hline 44 & .38 & .21 & .24 & .39 & .25 & .14 \\
\hline 104 & .50 & .32 & .26 & .37 & .26 & .18 \\
\hline 229 & .25 & .19 & -.12 & .36 & .11 & .07 \\
\hline 109 & .16 & -.06 & .11 & .34 & -.09 & -.15 \\
\hline 4 & .16 & -.01 & -.10 & .33 & .11 & .12 \\
\hline 177 & .63 & -.04 & -.17 & .12 & .78 & -.02 \\
\hline 237 & .40 & -.09 & .00 & .13 & .62 & .07 \\
\hline 147 & .44 & .02 & -.33 & .17 & .56 & -.10 \\
\hline 227 & .45 & .26 & -.11 & -.09 & .50 & .09 \\
\hline 122 & .36 & .11 & .11 & .23 & .49 & .05 \\
\hline 37 & .22 & .02 & .06 & .16 & .44 & .02 \\
\hline 71 & .30 & -.12 & .33 & .10 & -.38 & .00 \\
\hline 164 & .33 & .23 & .11 & .31 & .36 & -.08 \\
\hline 107 & .25 & .01 & -.04 & -.22 & .34 & .21 \\
\hline 142 & .20 & .12 & .01 & -.16 & .27 & .21 \\
\hline 1 & .05 & .04 & -.03 & .10 & -.20 & .03 \\
\hline 188 & .37 & .02 & .11 & .04 & -.09 & .63 \\
\hline 203 & .41 & .16 & -.04 & -.13 & .10 & .55 \\
\hline 23 & .36 & -.17 & -.13 & -.14 & .18 & .49 \\
\hline 98 & .31 & .14 & .24 & .02 & .08 & .46 \\
\hline 163 & .25 & .02 & -.23 & .15 & -.13 & .40 \\
\hline 128 & .13 & .01 & -.01 & .06 & -.10 & .36 \\
\hline 108 & .18 & .00 & -.02 & -.19 & .10 & .34 \\
\hline 28 & .15 & .04 & -.19 & .13 & .00 & .27 \\
\hline 93 & .06 & -.16 & .04 & .05 & .09 & .19 \\
\hline 197 & .09 & .10 & .01 & -.15 & .12 & .18 \\
\hline Eigenvalues & & 8.68 & 4.23 & 3.26 & 2.47 & 2.05 \\
\hline$\%$ Variance & & 14.47 & 7.06 & 5.43 & 4.12 & 3.42 \\
\hline
\end{tabular}

Note. Larger loadings are in bold for each component. Grey highlights the expected factor of each item. 